\title{
Validation of a $\tau-\omega$ model with Soil Moisture Active Passive Experiment (SMAPEx) data sets in Australia
}

\author{
$\underline{\text { Y. Gao }}^{a}$, J. P. Walker ${ }^{a}$, D. Ryu ${ }^{b}$, R. Panciera ${ }^{c}$, and A. Monerris ${ }^{a}$ \\ ${ }^{a}$ Department of Civil Engineering, Monash University, Clayton, Australia \\ ${ }^{b}$ Department of Infrastructure Engineering, University of Melbourne, Australia \\ ${ }^{c}$ Cooperative Research Centre for Spatial Information, Melbourne, Australia \\ Email: ying.gao@monash.edu
}

\begin{abstract}
There is a strong demand for soil moisture information in establishing efficient irrigation scheduling, climate change prediction, and sustainable land and water management. However, such data are not readily available with an appropriate accuracy or spatial and temporal resolution. Addressing the need for soil moisture at high resolution globally, the European Space Agency (ESA) has developed the Soil Moisture and Ocean Salinity (SMOS) mission. Launched in November 2009, SMOS provides the first satellite dedicated to near surface soil moisture measurement at $40-\mathrm{km}$ resolution. Moreover, the National Aeronautics and Space Administration (NASA) is developing the Soil Moisture Active Passive (SMAP) mission with a planned schedule for launch in October 2014. SMAP will deploy active (radar) and passive (radiometer) microwave instruments simultaneously to enhance soil moisture retrieval capabilities to a $10-\mathrm{km}$ resolution.
\end{abstract}

Both the SMOS and SMAP missions use a $\tau$ - $\omega$ model as the key component of their passive microwave soil moisture retrieval algorithms over moderately vegetated areas. While this model has been used in numerous L-band studies for soil moisture retrieval at various spatial scales throughout Europe, America and Australia, most studies have resulted in some "calibration" of model parameters or have proposed changes to the model physics. Consequently, this study presents an independent validation of the currently accepted version of the $\tau-\omega$ model using data from the first Soil Moisture Active Passive Experiment (SMAPEx-1) airborne campaign undertaken in south-eastern Australia in July 2010.

Designed specifically to support the development of soil moisture retrieval algorithms for the SMAP mission, SMAPEx-1 includes a series of intensive monitoring periods at the Yanco study area in south-eastern Australia. During these periods, data were collected from airborne radar and radiometer instruments concurrently with ground measurements of soil moisture, vegetation water content and surface roughness. In this paper, $1-\mathrm{km}$ soil moisture maps of the intensive monitoring areas were derived from airborne L-band passive (radiometer) data acquired from SMAPEx-1, and validated using extensive ground measurements of soil moisture. The comparison between measured and retrieved soil moisture content showed that the $\tau$ - $\omega$ model with the currently accepted parameters worked better for crops field than grassland. The RMSE for pixels with ancillary measurements was found to be $0.13 \mathrm{~m}^{3} \mathrm{~m}^{-3}$, which exceeds the SMAP target accuracy of $0.04 \mathrm{~m}^{3} \mathrm{~m}^{-3}$. With the $b$ parameter optimized for different land cover types, this number was reduced to 0.04 $\mathrm{m}^{3} \mathrm{~m}^{-3}$, and the bias reduced from 0.05 to $0.01 \mathrm{~m}^{3} \mathrm{~m}^{-3}$.

The contribution of this study is two-fold. First, it provides an independent test of the $\tau-\omega$ model for an independent set of soil and vegetation conditions. Second, the validated soil moisture data will be used as a baseline validation for many planned studies in support of SMAP, including radar-only soil moisture retrieval, active-passive soil moisture retrieval, validation of soil moisture downscaling, and testing scaling properties of the study area.

Keywords: soil moisture; $\tau$ - $\omega$ model; Soil Moisture Active Passive Experiment (SMAPEx); passive microwave; vegetation water content (VWC) 
Gao et al., Validation of a $\tau-\omega$ model with Soil Moisture Active Passive Experiment (SMAPEx) data sets...

\section{INTRODUCTION}

Soil moisture plays a fundamental role in the land surface hydrology, as it controls the exchange of water and heat energy between the land surface and the atmosphere through evaporation and plant transpiration. Estimating this variable with high temporal resolution and at the global scale has potential for application in meteorology, hydrology and climate research (Koster and Milly 1997; Dirmeyer et al. 2000; Loew 2008).

Research activities carried out worldwide in the past decade have proved that microwave radiometry at low frequency is a promising technique for estimating surface soil moisture. The Soil Moisture and Ocean Salinity (SMOS) mission from ESA, launched in 2009 carrying an L-band interferometric radiometer, was the first soil-moisture-specific passive microwave mission (Kerr et al. 2010). The multi-incidence angle and dual-polarization capabilities of the SMOS radiometer allows novel approaches for the retrieval of $0-5 \mathrm{~cm}$ soil moisture every 2-3 days at 40-km resolution globally (Kerr et al. 2010). In 2014, NASA will launch the Soil Moisture Active Passive (SMAP) mission with the aim of acquiring finer-resolution soil moisture measurements. The SMAP instrument incorporates an L-band radar and an L-band radiometer to enhance the surface soil moisture retrieval capabilities to a 10-km resolution (Entekhabi et al. 2010).

The retrieval of soil moisture from both SMOS and SMAP brightness temperatures $\left(\mathrm{T}_{\mathrm{B}}\right)$ are based on the socalled $\tau-\omega$ radiative transfer model. This model simulates the L-band emission from soil underlying a vegetation canopy, and has been found to be a meritorious approach through a large number of studies (eg. Wigneron et al. 2007). This paper tests the accuracy of the $\tau$ - $\omega$ model with the currently accepted state-ofthe-art model parameters from literature, using independent data from the first Soil Moisture Active Passive Experiment (SMAPEx-1) airborne campaign; see also Monerris et al. for further information about SMAPEx.

\section{DESCRIPTION OF THE DATA SET}

The SMAPEx-1 was conducted in the Yanco study area within the Murrumbidgee catchment in south-eastern Australia (Figure 1) between 5 and 10 July, 2010. It aims to provide both active and passive microwave airborne data supported by ground measurements of soil moisture, vegetation water content (VWC) and soil roughness. A total of 30 flight hours were conducted; only the passive microwave data has been used for this study. The wet winter conditions allowed observations of spatial variation in soil moisture in the range of $0.15-0.25 \mathrm{~m}^{3} \mathrm{~m}^{-3}$, with an approximate dynamic range of $0.05-0.1 \mathrm{~m}^{3} \mathrm{~m}^{-3}$ during the field experiment (Panciera 2011).

\subsection{Airborne data}

Brightness temperature $\left(T_{B}\right)$ data were acquired in three days $\left(6^{\text {th }}, 8^{\text {th }}\right.$ and $10^{\text {th }}$ of July $)$ at $1-\mathrm{km}$ resolution over the $40 \mathrm{~km} \times 40 \mathrm{~km}$ regional area, and over two target areas on the other two days ( $7^{\text {th }}$ and $9^{\text {th }}$ of July) at $100-\mathrm{m}$ resolution (see Figure 1) using the Polarimetric L-band Multibeam Radiometer (PLMR). The accuracy of PLMR calibration was estimated to be better than $1 \mathrm{~K}$ at $\mathrm{H}$ polarization and $2.5 \mathrm{~K}$ at $\mathrm{V}$ polarization. Data used in this study are only the 1-km resolution data over the six intensive monitoring areas: YA4, YA7, YC, YD, YB5 and YB7 as shown in Figure 1. Since each regional flight was conducted through a time span of approximately 2-3 hours and the geometry of PLMR resulted in three different viewing angles, all the $T_{B}$ data have been standardized to the soil profile temperature in the middle of the flight period and to an angle of $38.5^{\circ}$, which represents the outer left beam of PLMR and the approximate incidence angle of SMAP. The soil profile temperatures used for the standardization were obtained from the ground monitoring sites: the surface temperature at $2.5 \mathrm{~cm}\left(T_{S U R F}\right)$ from the SMAPEx and temporary stations, and the deep temperature at $40 \mathrm{~cm}\left(T_{D E P T H}\right)$ from temporary monitoring stations only (see Table 1$)$.

\subsection{Ground soil moisture data}

Spatial ground soil moisture sampling was undertaken concurrently with each flight during SMAPEx-1. When regional flights were conducted, sampling was undertaken on a regular grid of $250 \mathrm{~m}$-spaced locations in two of the six intensive $3 \mathrm{~km} \times 3 \mathrm{~km}$ monitoring areas. When targets flights were conducted, soil moisture sampling were undertaken along ten $50 \mathrm{~m}$-spaced transects within two target areas. The equipment used for soil moisture measurement was the Hydraprobe Data Acquisition System (HDAS) which is an efficient spatial data acquisition tool that allows sampling at predefined locations and collects real-time data including soil moisture, soil temperature and some user-prompted observations such as land cover type. For all sampling locations, three surface soil moisture measurements were taken, which allowed the minimisation of random errors from local scale. In this study, each intensive monitoring area included a $3 \mathrm{~km} \times 3 \mathrm{~km}$ grid. Subsequently, the average soil moisture content of each $1-\mathrm{km}$ pixel was calculated together with the standard deviation (see Table 1). It should be noted that the data was quality controlled, such that if among the three 


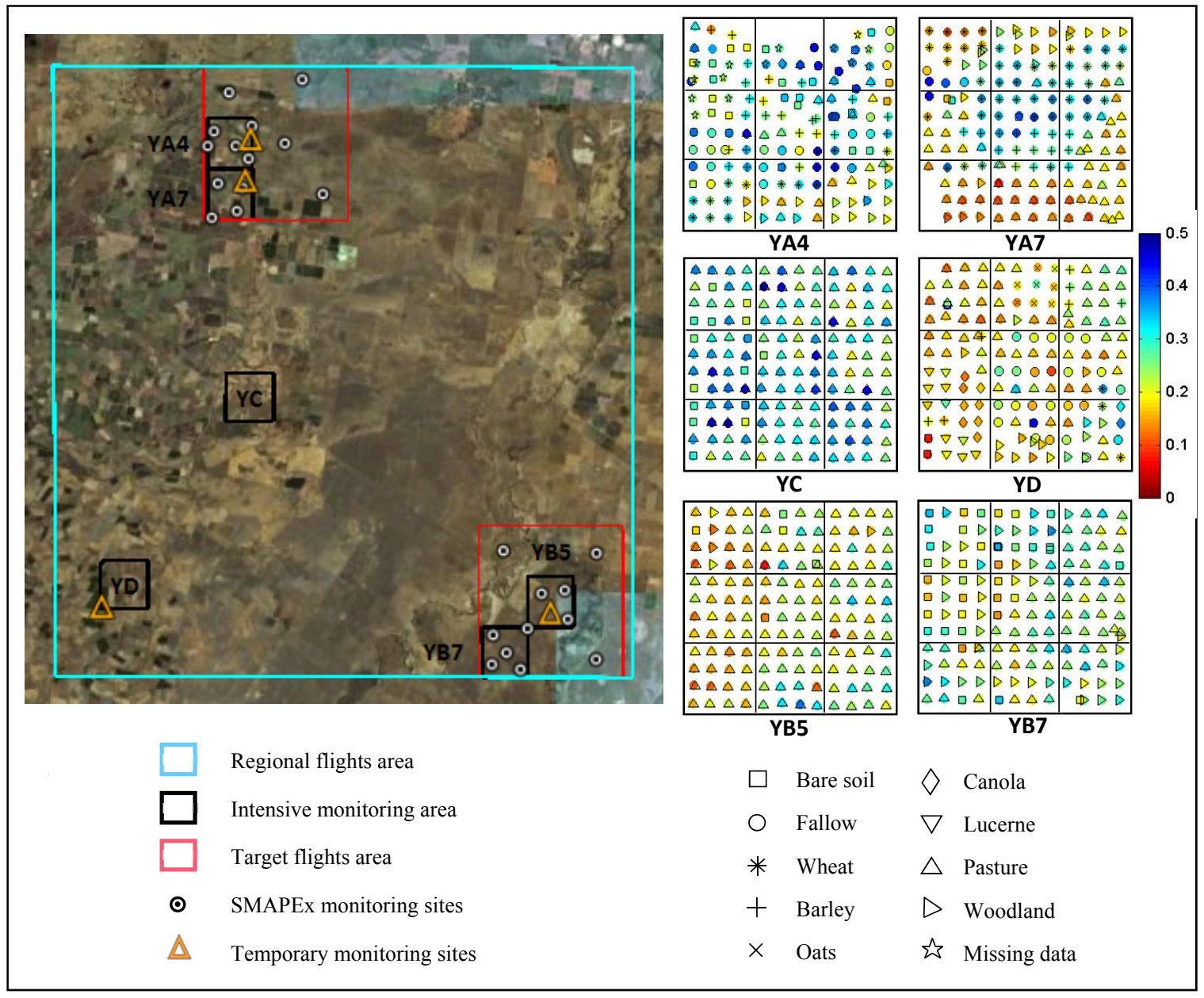

Figure 1. (Left) Layout of the SMAPEx study area showing airborne coverages and intensive ground sampling areas together with ground monitoring stations; (Right) The soil moisture sampling values and vegetation cover of the six focus areas. Each focus area contains 9 pixels.

measurements of a certain location, there was one value which appeared to be very different from the other two, such a value was removed from the analysis.

\subsection{VWC and land cover mapping}

Destructive vegetation samples were collected at various locations across the $3 \mathrm{~km} \times 3 \mathrm{~km}$ focus study areas, aiming to characterize all the dominant vegetation types present. In each area, the major vegetation types were characterised by making measurements at 3 (minimum 1) locations distributed within homogeneous paddocks. The average VWC and standard deviation were calculated (see Table 1) for those vegetation samples which fell into 1-km pixels across the focus sampling areas.

Since very few pixels actually had a measured VWC, the small-scaled land cover mapping across the focus areas during the soil moisture sampling (Figure 1) was used to estimate the VWC for unobserved pixels. Almost all the area of YC, YB5 and part of the area of YB7 are covered by grass. Consequently, the pixels involved in the unobserved pixels of these areas were estimated from the measured VWC of pasture. Similarly, YA4, YA7 and YD were a mixture of land cover types, and likewise the VWC of the pixels involved in these areas was estimated using the dominant vegetation type of that pixel. This strategy provides a complete VWC map for the six areas under study to be used as input to the $\tau$ - $\omega$ model.

\section{THE TAU-OMEGA MODEL}

\subsection{Model description}

The $\tau$ - $\omega$ model is based on two parameters: the optical depth of the canopy $\tau(\mathrm{Np})$, and the single-scattering 
Gao et al., Validation of a $\tau-\omega$ model with Soil Moisture Active Passive Experiment (SMAPEx) data sets...

Table 1. Average and standard deviation (SD) of soil moisture, VWC and soil temperature together with the average observed airborne $T_{B}$ values for $1 \mathrm{~km}$ resolution pixels at focus farms with all ancillary data measured.

\begin{tabular}{|c|c|c|c|c|c|c|c|c|c|c|c|}
\hline Date & Site & $\begin{array}{l}\text { Pixel } \\
\text { No. }{ }^{[1]}\end{array}$ & $\begin{array}{l}\text { Dominant } \\
\text { land } \\
\text { cover }\end{array}$ & $\begin{array}{c}\text { Soil } \\
\text { moisture } \\
\text { mean } \\
(\mathrm{v} / \mathrm{v})\end{array}$ & $\begin{array}{c}\text { Soil } \\
\text { moisture } \\
\text { SD (v/v) }\end{array}$ & $\begin{array}{c}\text { VWC } \\
\text { mean } \\
\left(\mathrm{kg} / \mathrm{m}^{2}\right)\end{array}$ & $\begin{array}{c}\text { VWC SD } \\
\left(\mathrm{kg} / \mathrm{m}^{2}\right) / \mathrm{No} . \\
\text { samples }\end{array}$ & $\begin{array}{c}T_{S U R F} \\
\left({ }^{\circ} \mathrm{C}\right)\end{array}$ & $\begin{array}{c}T_{D E P T H} \\
\quad\left({ }^{\circ} \mathrm{C}\right)\end{array}$ & $\begin{array}{l}T_{B V} \\
(\mathbf{K})\end{array}$ & $\begin{array}{l}T_{B H} \\
(\mathbf{K})\end{array}$ \\
\hline \multirow{7}{*}{ 06-Jul } & YA4 & 1 & Bare soil & 0.26 & 0.09 & 0.097 & {$[2]$} & \multirow{7}{*}{$\begin{array}{c}12.2 \pm \\
0.9\end{array}$} & \multirow{7}{*}{$\begin{array}{c}9.7 \pm \\
0.3\end{array}$} & 245.1 & 214.2 \\
\hline & YA4 & 3 & Fallow & 0.34 & 0.09 & 1.856 & $0.098 / 3$ & & & 239.9 & 205.9 \\
\hline & YA4 & 4 & Barley & 0.29 & 0.08 & 0.120 & $0.021 / 2$ & & & 245.4 & 213.9 \\
\hline & YA4 & 5 & Barley & 0.27 & 0.07 & 0.200 & $0.232 / 2$ & & & 247.5 & 213.2 \\
\hline & YA4 & 8 & Pasture & 0.28 & 0.10 & 1.016 & - & & & 239.6 & 206.6 \\
\hline & YB7 & 5 & Pasture & 0.24 & 0.06 & 0.528 & - & & & 232.3 & 197.1 \\
\hline & YB7 & 6 & Pasture & 0.26 & 0.06 & 0.478 & $0.109 / 2$ & & & 230.7 & 200.6 \\
\hline \multirow{7}{*}{ 08-Jul } & $\mathrm{YC}$ & 4 & Pasture & 0.34 & 0.05 & 0.125 & - & \multirow{7}{*}{$\begin{array}{c}13.3 \pm \\
1.5\end{array}$} & \multirow{7}{*}{$\begin{array}{c}9.5 \pm \\
0.3\end{array}$} & 226.2 & 192.4 \\
\hline & $\mathrm{YC}$ & 5 & Pasture & 0.33 & 0.10 & 0.806 & - & & & 228.3 & 197.3 \\
\hline & $\mathrm{YC}$ & 7 & Pasture & 0.32 & 0.08 & 0.716 & - & & & 242.5 & 209.6 \\
\hline & YD & 2 & Oats & 0.18 & 0.05 & 0.026 & $0.011 / 3$ & & & 248.6 & 214.1 \\
\hline & YD & 4 & Pasture & 0.18 & 0.04 & 0.496 & $0.176 / 3$ & & & 248.0 & 214.2 \\
\hline & YD & 6 & Pasture & 0.20 & 0.07 & 2.023 & $0.241 / 3$ & & & 247.3 & 214.4 \\
\hline & YD & 7 & Lucerne & 0.16 & 0.05 & 0.390 & $0.251 / 5$ & & & 255.3 & 221.2 \\
\hline \multirow{4}{*}{ 10-Jul } & YA7 & 1 & Wheat & 0.23 & 0.11 & 0.056 & - & \multirow{4}{*}{$\begin{array}{c}9.9 \pm \\
0.4\end{array}$} & \multirow{4}{*}{$\begin{array}{c}9.9 \pm \\
0.5\end{array}$} & 239.8 & 210.5 \\
\hline & YB5 & 2 & Pasture & 0.22 & 0.08 & 0.118 & - & & & 243.0 & 213.5 \\
\hline & YB5 & 5 & Pasture & 0.20 & 0.05 & 0.169 & - & & & 239.0 & 208.8 \\
\hline & YB5 & 6 & Pasture & 0.21 & 0.06 & 0.121 & - & & & 238.7 & 207.3 \\
\hline
\end{tabular}

${ }^{[1]}$ Pixels of each intensive monitoring area were numbered consecutively from left to right, row-wise top to bottom.

[2]، '- means there was only one sample taken from that pixel.

albedo $\omega(-)$, which are used to parameterize the vegetation attenuation properties and the scattering effects within the canopy layer. In this model, the $T_{B}(\mathrm{~K})$ of a mixed soil and vegetation medium is, for each polarization $P$, modeled as the contribution of three terms: the upward soil emission attenuated by the canopy, the direct upward vegetation emission, and the downward vegetation emission that is reflected by the soil and then attenuated by the canopy (Mo et al. 1982; Dirmeyer et al. 2000; Wigneron et al. 2007). This translates into:

$$
T_{B P}=\left(1-\omega_{P}\right)\left(1-\gamma_{P}\right)\left(1+\gamma_{P} r_{P}\right) \mathrm{T}_{\mathrm{V}}+\left(1-r_{P}\right) \gamma_{P} T_{E F F}
$$

where $T_{E F F}(\mathrm{~K})$ and $T_{V}(\mathrm{~K})$ are the effective soil and vegetation temperatures, $\omega$ and $\gamma(-)$ are the single scattering albedo and the vegetation transmissivity, and $r(-)$ is the soil emissivity.

The transmissivity $\gamma$ is determined by

$$
\gamma_{P}=\exp \left[-\tau_{\mathrm{NAD}}\left(\cos ^{2} \theta+\mathrm{tt}_{\mathrm{P}} \sin ^{2} \theta\right) / \cos \theta\right],
$$

where $\tau_{N A D}(\mathrm{~Np})$ is the vegetation optical depth at nadir, $t t_{P}(-)$ corrects the optical depth for non-nadir views at each polarization and $\theta$ (degrees) is the sensor observation angle. The vegetation optical depth $\tau_{N A D}$ was found to be related linearly to the VWC using the $b(-)$ parameter through $\tau_{N A D}=b^{*} \mathrm{VWC}$ (Jackson and Schmugge 1991; Van de Griend and Wigneron 2004).

The soil reflectivity $r$ is determined by the soil roughness parameters $H_{R}(-)$ and $N_{R P}(-)$ as

$$
r=r^{*} \exp \left[-H_{R} \cos (\theta)^{N_{R P}}\right],
$$

where the smooth soil reflectivity $r^{*}$ is related to the surface soil moisture content through the Fresnel equations and a dielectric constant model. The Dobson dielectric mixing model, which takes into account soil textual properties to simulate the dielectric behavior of the soil-water mixture when the sand fraction does not exceed 90\%, was used in this study (Dobson et al. 1985). 
Gao et al., Validation of a $\tau$ - $\omega$ model with Soil Moisture Active Passive Experiment (SMAPEx) data sets...

Table 2. Default model values and optimised $b$ values for different landcovers. Superscripts show the source of default parameter values.

\begin{tabular}{|c|c|c|c|c|c|c|c|c|c|}
\hline \multirow{2}{*}{ Landcover } & \multicolumn{8}{|c|}{ Default model parameters } & \multirow{2}{*}{$\begin{array}{l}\text { Optimised } b \\
\text { with } H_{R} \text { fixed }\end{array}$} \\
\hline & $H_{R}$ & $N_{R H}$ & $N_{R V}$ & $t t_{H}$ & $t t_{V}$ & $\omega_{H}$ & $\omega_{V}$ & $b$ & \\
\hline Fallow & $0.1^{[1]}$ & $1^{[1]}$ & $0^{[1]}$ & $1^{[1]}$ & $1^{[1]}$ & $0^{[1]}$ & $0^{[1]}$ & $0.12^{[1][2]}$ & 0.10 \\
\hline Barley & \multirow{4}{*}{$0.2^{[1]}$} & \multirow{4}{*}{$1^{[1]}$} & \multirow{4}{*}{$0^{[1]}$} & \multirow{4}{*}{$\begin{array}{l}1^{[1]} \\
0.2^{[4]} \\
1^{[1]} \\
1^{[1]}\end{array}$} & \multirow{4}{*}{$\begin{array}{l}1^{[1]} \\
0.4^{[4]} \\
1^{[1]} \\
1^{[1]}\end{array}$} & \multirow{4}{*}{$0^{[1]}$} & \multirow{4}{*}{$0^{[1]}$} & \multirow{4}{*}{$0.08^{[2]}$} & 1.20 \\
\hline Wheat & & & & & & & & & 0.50 \\
\hline Oats & & & & & & & & & 0.06 \\
\hline Canola & & & & & & & & & 0.10 \\
\hline Lucerne & \multirow{2}{*}{$0.4^{[5]}$} & \multirow{2}{*}{$1^{[5]}$} & \multirow{2}{*}{$0^{[5]}$} & \multirow{2}{*}{$1^{[5]}$} & \multirow{2}{*}{$1^{[5]}$} & \multirow{2}{*}{$0^{[5]}$} & \multirow{2}{*}{$0^{[5]}$} & \multirow{2}{*}{$0.15^{[3]}$} & 0.06 \\
\hline Pasture & & & & & & & & & 0.06 \\
\hline
\end{tabular}

The soil effective temperature is determined as a function of two temperature measurements: one at soil surface $(2-5 \mathrm{~cm}) T_{\text {SURF }}$, the other at a greater depth $(\sim 50 \mathrm{~cm}) T_{D E P T H}$ as

$$
T_{E F F}=T_{D E P T H}+\left(T_{S U R F}-T_{D E P T H}\right) *\left(\theta / w_{0}\right)^{b_{0}},
$$

where $\theta$ is the surface soil moisture at about $0-2 \mathrm{~cm}, w_{0}$ and $b_{0}$ are semiempirical parameters depending on specific soil characteristics. Parameters $w_{0}=0.398$ and $b_{0}=0.181$ were calibrated from a study with similar soil properties (Wigneron et al. 2008) and applied in this study. $\mathrm{T}_{\mathrm{SURF}}$ and $\mathrm{T}_{\mathrm{DEPTH}}$ are the temperature values described in a previous section.

\subsection{Validation and optimization}

Since the main objective of this paper is to assess the currently accepted parameters of the $\tau$ - $\omega$ model, the default model parameters were derived from a literature review for the different land cover type and are given in Table 2. Generally, three land cover groups were characterized: fallow (or bare soil), crop (barley, wheat, oats and canola) and grass (lucerne and pasture), and for each group similar parameters were applied according to the literature.

Apart from the validation of default parameters, the $b$ parameter was calibrated for each land cover type. Although it has been justified in previous studies (Panciera et al. 2009) that it is more reasonable to calibrate $H_{R}$ alone, the accuracy target $0.04 \mathrm{~m}^{3} \mathrm{~m}^{-3}$ was best met by calibration of $\mathrm{b}$ with $H_{R}$ fixed. Consequently, it was assumed that the default value of parameter $H_{R}$ proposed for each land cover type is correct and thus the error in retrieval was from $b$ alone. The calibrated values of $b$ are presented in Table 2.

\section{RESULTS AND DISCUSSION}

The soil moisture retrieval was first evaluated using the default model values. Soil moisture was retrieved at $1-\mathrm{km}$ resolution over the six intensive monitoring areas using a two channel retrieval ( $\mathrm{H}-$ pol and $\mathrm{V}$-pol) on each $\mathrm{T}_{\mathrm{B}}$ observation. The resulting soil moisture was compared to the mean value of the ground measured soil moisture. Figure 2 shows the scatter plot between retrieved and ground observed soil moisture using default parameters. The vertical error bars indicate the standard deviation of the ground observed soil moisture while the icons indicate the mean soil moisture value for each area and its vegetation type. In contrast to earlier validation studies (eg. Panciera et al. 2009), it can be seen that crop sites show better results compared to grassland and fallow. The Root Mean Square Error (RMSE) for the crop sites was calculated to be $0.14 \mathrm{~m}^{3} \mathrm{~m}^{-3}$, while that of the pasture and fallow sites was $0.07 \mathrm{~m}^{3} \mathrm{~m}^{-3}$. Over grassland and fallow, there is a tendency to overestimate soil moisture. This error could be due to the fact that land cover in the grassland was highly heterogeneous and the pasture in Australia may have quite different biophysical features compared to the pastures in the USA where the $b$ value was originally derived. Conversely, a tendency of underestimating the soil moisture ocurred with barley and wheat. However, this error is not as significant as that of grassland. Both the RMSE between retrieved and observed soil moisture for all pixels and only those pixels with measured ancillary data $\left(0.13 \mathrm{~m}^{3} \mathrm{~m}^{-3}\right.$ and $0.12 \mathrm{~m}^{3} \mathrm{~m}^{-3}$ respectively) do not suggests a fullfilment of the target accuracy. 

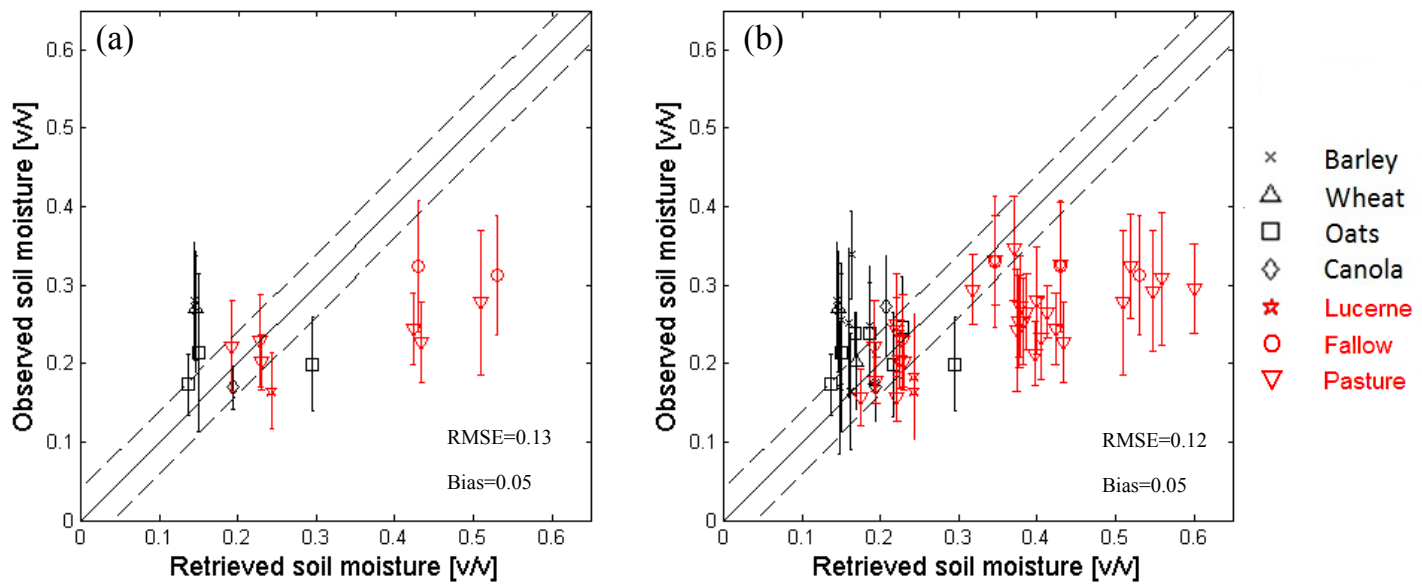

Figure 2. Evaluation of soil moisture retrieval using default parameters including (a) only pixels with measured ancillary data and (b) all pixels from the intensive monitoring areas. Black dashed lines indicated the SMAP target accuracy $\left(0.04 \mathrm{~m}^{3} \mathrm{~m}^{-3}\right)$. Fallow (or bare soil) sites and grass sites are shown in red.

The scatter plot between retrieved and ground observed soil moisture after optimisation of the $b$ value is presented in Figure 3. By lowering the $b$ value of grassland and fallow, and raising it for barley and wheat, it is clearly seen that the RMSE of pixels with ancillary measurements was reduced to $0.04 \mathrm{~m}^{3} \mathrm{~m}^{-3}$ which satisfies the target accuracy. On the other hand, the RMSE of all pixels was also reduced by one half, being very close to the SMAP target accuracy. However, such calibration studies are not practical for global satellite retrieval, meaning that further work on global parameter sets is still required.

\section{CONCLUSION}

It can be concluded that the current default parameters of the $\tau$ - $\omega$ model did not work well for the data from the SMAPEx-1 campaign. Compared with the retrieval results for crops, larger errors occurred for grassland and fallow pixels. It also suggested that the $\tau-\omega$ model with the current accepted $b$ values tend to overestimate the soil moisture for grassland. This result shows discrepancies with previous studies which showed a good match for grassland but large errors in crops. Nevertheless, it was found in this study that for grassland with a default $H_{R}$ value equal to 0.4 , the best $b$ value should be 0.06 instead of 0.15 . Further evaluations of these parameters are required in order to confirm this result.
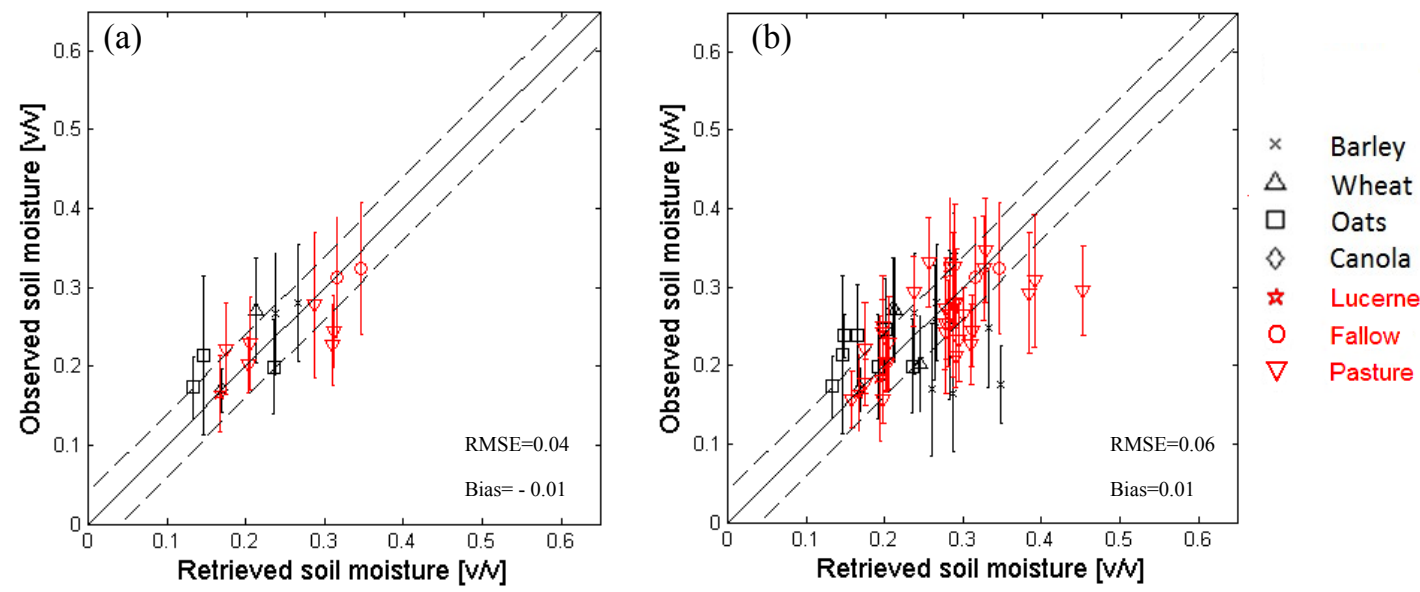

Figure 3. The same as Figure 2 but with optimised parameters. 
Gao et al., Validation of a $\tau$ - $\omega$ model with Soil Moisture Active Passive Experiment (SMAPEx) data sets...

\section{ACKNOWLEDGMENTS}

The authors would like to thank all the SMAPEx-1 participants and the funding from ARC grant DP0984586.

\section{REFERENCES}

Dirmeyer, P. A., F. J. Zeng, A. Ducharne, J. C. Morrill and R. D. Koster (2000). The sensitivity of surface fluxes to soil water content in three land surface schemes. Journal of Hydrometeorology 1(2): 121134.

Dobson, M. C., F. T. Ulaby, M. T. Hallikainen and M. A. Elrayes (1985). Microwave dielectric behavior of wet soil. 2. Dielectric mixing models. IEEE Transactions on Geoscience and Remote Sensing 23(1): 35-46.

Entekhabi, D., E. G. Njoku, P. E. O'Neill, K. H. Kellogg, W. T. Crow, W. N. Edelstein, J. K. Entin, S. D. Goodman, T. J. Jackson, J. Johnson, J. Kimball, J. R. Piepmeier, R. D. Koster, N. Martin, K. C. McDonald, M. Moghaddam, S. Moran, R. Reichle, J. C. Shi, M. W. Spencer, S. W. Thurman, L. Tsang and J. Van Zyl (2010). The Soil Moisture Active Passive (SMAP) Mission. Proceedings of the IEEE 98(5): 704-716.

Jackson, T. J. and T. J. Schmugge (1991). Vegetation effects on the microwave emission of soils. Remote Sensing of Environment 36(3): 203-212.

Kerr, Y. H., P. Waldteufel, J.-P. Wigneron, S. Delwart, F. Cabot, J. Boutin, M.-J. Escorihuela, J. Font, N. Reul, C. Gruhier, S. E. Juglea, M. R. Drinkwater, A. Hahne, M. Martin-Neira and S. Mecklenburg (2010). The SMOS Mission: New Tool for Monitoring Key Elements of the Global Water Cycle. Proceedings of the IEEE 98(5): 666-687.

Koster, R. D. and P. C. D. Milly (1997). The interplay between transpiration and runoff formulations in land surface schemes used with atmospheric models. Journal of Climate 10(7): 1578-1591.

Loew, A. (2008). Impact of surface heterogeneity on surface soil moisture retrievals from passive microwave data at the regional scale: The Upper Danube case. Remote Sensing of Environment 112(1): 231248.

Mo, T., B. J. Choudhury, T. J. Schmugge, J. R. Wang and T. J. Jackson (1982). A model for microwave emission from vegetation-covered fields. Journal of Geophysical Research-Oceans and Atmospheres 87(NC13): 1229-1237.

Monerris A., Walker, J.P., Panciera, R., Jackson, T.J., Gray, D., Yardley, H., Ryu, D (2011). The third Soil Moisture Active Passive Experiment. submitted.

Panciera, R. (2011, June). Experiment Overview. Welcome to the SMAPEx-1 experiment. Retrieved July 10, 2011, from http://www.smapex.monash.edu.au/SMAPEx-1.php.

Panciera, R., Walker, J.P., Ryu, D., Gray, D., and Jackson, T.J. (2010a). The Soil Moisture Active Passive Experiments Workplan. [Online]. Available: http://www.smapex.monash.edu.au/Data/SMAPEx1/SMAPEx_workplan_final.pdf

Panciera, R., J. P. Walker, J. D. Kalma, E. J. Kim, K. Saleh and J. P. Wigneron (2009). Evaluation of the SMOS L-MEB passive microwave soil moisture retrieval algorithm. Remote Sensing of Environment 113(2): 435-444.

Peischl, S., J. Walker, D. Ryu, Y. Kerr, R. Panciera and C. Rüdiger (2011). Wheat canopy structure and surface roughness effects on multi-angle observations at L-band. submitted.

Saleh, K., Y. H. Kerr, P. Richaume, M. J. Escorihuela, R. Panciera, S. Delwart, G. Boulet, P. Maisongrande, J. P. Walker, P. Wursteisen and J. P. Wigneron (2009). Soil moisture retrievals at L-band using a two-step inversion approach (COSMOS/NAFE'05 Experiment). Remote Sensing of Environment 113(6): 1304-1312.

Saleh, K., J. P. Wigneron, P. Waldteufel, P. de Rosnay, M. Schwank, J. C. Calvet and Y. H. Kerr (2007). Estimates of surface soil moisture under grass covers using L-band radiometry. Remote Sensing of Environment 109(1): 42-53.

Van de Griend, A. A. and J. P. Wigneron (2004). The b-factor as a function of frequency and canopy type at h-polarization. IEEE Transactions on Geoscience and Remote Sensing 42(4): 786-794.

Wigneron, J. P., A. Chanzy, P. de Rosnay, C. Rudiger and J. C. Calvet (2008). Estimating the effective soil temperature at L-band as a function of soil properties. IEEE Transactions on Geoscience and Remote Sensing 46(3): 797-807.

Wigneron, J. P., Y. Kerr, P. Waldteufel, K. Saleh, M. J. Escorihuela, P. Richaume, P. Ferrazzoli, P. de Rosnay, R. Gurney, J. C. Calvet, J. P. Grant, M. Guglielmetti, B. Hornbuckle, C. Matzler, T. Pellarin and M. Schwank (2007). L-band Microwave Emission of the Biosphere (L-MEB) Model: Description and calibration against experimental data sets over crop fields. Remote Sensing of Environment 107(4): 639-655. 